\title{
Polygenic adaptation is not a major driver of disparities in disease mortality across global populations
}

\author{
Ujani Hazra ${ }^{1}$ and Joseph Lachance ${ }^{1 *}$ \\ ${ }^{1}$ School of Biological Sciences, Georgia Institute of Technology, Atlanta Georgia, USA \\ ${ }^{*}$ Corresponding author: \\ Email addresses of authors: \\ ujani.hazra@gatech.edu \\ joseph.lachance@biology.gatech.edu
}

Keywords: evolutionary genetics, health disparities, natural selection, polygenic risk scores, polygenic adaptation

Running title: polygenic adaptation and health disparities 


\section{Abstract}

Background and objectives: Health disparities are due to a range of socioeconomic and biological causes, and many common diseases have a genetic basis. Divergent evolutionary histories cause allele frequencies at disease-associated loci to differ across global populations. To what extent are differences in disease risks due to natural selection?

Methodology: Examining a panel of nine global populations, we identified which of the 20 most common causes of death have the largest health disparities. Polygenic risk scores were computed and compared for 11 common diseases for the same nine populations. We then used PolyGraph to test whether differences in disease risk can be attributed to polygenic adaptation. Finally, we compared human development index statistics and polygenic risk scores to mortality rates for each population.

Results: Among common causes of death, HIV/AIDS and tuberculosis exhibited the greatest disparities in mortality rates. Focusing on common polygenic diseases, we found that genetic predictions of disease risk varied across global populations (including elevated risks of lung cancer in Europeans). However, polygenic adaptation tests largely yielded negative results when applied to common diseases. Our analyses revealed that natural selection was not a major cause of differences in disease risks across global populations. We also found that correlations between mortality rates and human development index statistics were stronger than correlations between mortality rates and polygenic predictions of disease risks.

Conclusions and implications: Although evolutionary history contributes to differences in disease risks, health disparities are largely due to socioeconomic and other environmental factors. 


\section{Background and Objectives}

Epidemiological analyses have reported major disparities in disease prevalence, incidence, and mortality rates across global populations and ethnic groups (1-3). Environment and lifestyle changes have been known to drive disease risks across populations since the Neolithic revolution when societies shifted from foraging to cultivating food. Increases in population size and changes in eating habits following the agricultural revolution led to an increase in nutritional and infectious diseases and a decline in the overall health of populations (4). While mortality rates from infectious diseases have decreased significantly in the 20th century (ㅁ), the "transition to modernity" (므) now puts the global population at a greater risk of non-communicable diseases. A recent study of Sub-Saharan African populations has shown that the leading causes of death have changed between 1990 and 2010 from communicable diseases in children to non-communicable diseases in adults, with stroke, depression, diabetes, and ischemic heart disease dominating among upper-middle-income countries (7). However, the increased prevalence and mortality rates of non-communicable diseases are not uniform worldwide. Disease burdens of stroke and ischemic heart disease vary greatly across global populations (ㅇ) . Other studies have reported that men of African descent suffer the highest mortality from prostate cancer globally, indicating geographic and ethnic disparities (ㅁ).

Disparities in disease prevalence and mortality rates are due to a complex combination of socioeconomic, demographic, environmental, and genetic causes. Socioeconomic factors like poverty and lack of access to quality treatment have increased chronic kidney disease risks, in addition, to an already established racial and ethnic disparities (10). Similarly, environmental factors like exposure to abandoned uranium mines have increased risks of hypertension, kidney disease, and cancer in some Native American populations (11). It should be noted that such disease-causing factors are often interdependent and act synergistically to influence disease risk. A population's genetic makeup can also make them susceptible to certain diseases. For example, people of 
Ashkenazi descent have a higher frequency of the $B R C A 1 / 2$ mutations, subjecting them to higher risks of breast cancer (12).

Unlike monogenic diseases like sickle cell anemia or cystic fibrosis, most high mortality non-communicable diseases (e.g., stroke, chronic kidney disease, and diabetes) are polygenic in nature, i.e., the risks of many complex diseases are due to multiple genetic variations or single nucleotide polymorphisms (SNPs). Evolutionary history, including natural selection and founder effects (13-15), can cause allele frequencies of diseaseassociated SNPs to vary among populations. These allele frequency differences can, in turn, cause hereditary disease risks to vary across the globe. With the advent of genome-wide association studies (GWAS), large numbers of disease-associated SNPs are now known (16), and these SNPs can be used to generate polygenic predictions of disease risk (17, 18). Importantly, shifts in allele frequencies at trait-associated SNPs can be used to detect natural selection acting on polygenic diseases (19).

In this paper, we integrate country-level epidemiological data, genetic data from nine global populations, and GWAS findings to address the following questions: Which common causes of death exhibit the greatest disparities in mortality rates? To what extent do polygenic predictions of disease risk vary across global populations? Has natural selection been a major cause of differences in the risks of common hereditary diseases? Are disparities in mortality rates better attributed to socioeconomic or genetic factors?

\section{Methodology}

\section{Public Health Data: Disparities in Development and Mortality Rate}

We collated the top 20 global causes of death (Table 1) and mortality rate data from the World Health Organization (WHO) report for 2019 (20), filtering and removing the nondiseased traits like road injury, falls, and self-harm. Of the 17 disease traits, we removed neonatal conditions, infectious diseases (diarrhea, tuberculosis, lower respiratory infection, and HIV/AIDS), cirrhosis of the liver, and stomach cancer due to 
the lack of large numbers of publicly available GWAS SNPS. This left us with a final list of 10 diseases out of the 20 most common global causes of death. Diabetes mellitus was split into type 1 and type 2 diabetes, to accommodate different GWAS for each type of disease, resulting in a total of 11 diseases analyzed here.

Country-specific mortality rates vary for the top 20 causes of death reported by WHO. To study the disparities in these mortality rates, we focused on nine populations from the 1000 Genomes Project (1KGP), which have well-defined country-level disease mortality data and cover each of the major continental super populations. The nine representative countries and populations in this study are the United Kingdom (GBR), Spain (IBS), Nigeria (YRI), Sierra Leone (MSL), Bangladesh (BEB), Sri Lanka (STU), China (CHB), Japan (JPT), and Peru (PEL).

To quantify the extent of health disparities, coefficients of variation (CV) of agestandardized mortality rates were calculated among countries for each of the 20 most common global causes of death:

$$
C V=\sigma / \mu
$$

where $\sigma$ is the standard deviation and $\mu$ is the mean of mortality rates in the nine populations (Table 1). We also obtained 2019 Human Development Index (HDI) statistics from the United Nations Development Programme, Human Development Reports (21) to study whether a country's socioeconomic and development status play a role in determining mortality from certain diseases. Linear regression methods were applied to examine correlations between the HDI and mortality rates for the top 20 causes of death over the nine representative populations.

\section{Genetic Data: Population Admixture and Disease Associations}

Phase 3 data from the 1KGP was used as a reference for building admixture graphs and calculating polygenic risk scores. To study polygenic adaptation, publicly available summary statistics of 11 genome-wide association studies (22-32) were collated (Table 2), with diabetes mellitus having representative GWAS for type 1 and type 2 diabetes. We only considered GWAS SNPs with a p-value $<5 \times 10^{-8}$ (Table 2). LiftOver (33) was 
used to convert the coordinates of all GWAS SNPs to the hg19 build for integration with the Phase 3 data from the 1KGP.

\section{Predicting differences in disease risks}

Predicted polygenic disease risks were calculated via polygenic risk scores (PRS). Risk scores were calculated for the 11 GWAS statistics in the nine representative populations using the Phase 3 data from the 1KGP. As per standard practice (18), PRS for each individual were calculated as:

$$
P R S=\sum_{i} N_{i} \beta_{i}
$$

where $N_{i}$ is an individual's dosage of the effect allele $(N=0,1$ or 2$)$ of the $i^{\text {th }}$ SNP and $\beta_{i}$ is the effect size of each SNP. PRS was then converted to a standardized normal (i.e., z-score) scale, with a global mean of zero and standard deviation of one.

Differences in predicted polygenic disease risk distribution between European (GBR and IBS) and non-European (BEB, STU, CHB, JPT, YRI, MSL) populations were compared using Mann-Whitney U-tests. The Mann-Whitney U-test assumes that the two groups being compared (European vs. non-European in this case) are independent. Since PEL is an admixed population, we exclude it from the Mann-Whitney U-Test to keep the two groups independent. Correlations of mortality rates with predicted polygenic disease risk scores were studied for the 11 diseases over the nine representative populations.

\section{Examining Polygenic Adaptation}

To investigate signals of polygenic adaptation, we used PolyGraph (34), A Markov Chain Monte Carlo (MCMC) algorithm that utilizes admixture graph information to deduce traces of polygenic adaptation in populations. To detect selection on a trait PolyGraph requires a set of summary statistics from GWAS, neutral control SNPs that are not associated with the trait, and an admixture graph of the representative populations. Since PolyGraph estimates adaptation based on ancestral and derived states of SNPS, it is required to have the knowledge of ancestral alleles of all the GWAS 
hits and polarize the effect sizes of SNPs based on the derived allele. Thus, only GWAS hits for which ancestral allele information was available from the 1KGP dataset were used in our study. Odds-ratios (OR) reported by some GWASs were converted to effect sizes, where $\beta=\ln (\mathrm{OR})$.

Next, we used SNPsnap ( $\underline{35}$ ) to obtain frequency-matched neutral SNPs for the GWAS hits. We frequency matched the GWAS SNPs with European, East Asian, and West African populations from the $1 \mathrm{KGP}$, and pooled from these three sets to make a universal set of neutral/control SNPs for each trait. The same set of neutral SNPs was used to build an admixture graph using MixMapper (36). We made scaffold trees with eight continental populations and putatively added the population from Peru (PEL) as an admixed population (note that the one branch leading to PEL represents Native American ancestry). For each disease, PolyGraph reports a positive selection parameter alpha, which is a product of the selection coefficient for the advantageous allele and the duration of the selective process (4ㄴ), and a p-value for selection on the entire admixture graph. To correct for multiple testing, we calculated FDR-adjusted qvalues from the overall p-values of selection from PolyGraph.

\section{Results}

\section{Disparities in Mortality Rates and Development Index}

The top 20 causes of death as of 2019 show considerable variation in mortality rates worldwide (Table 1). The largest disparities were observed for lower respiratory infections $(C V=1.05)$, neonatal disease $(C V=1.177)$, diarrhea $(C V=1.575)$, tuberculosis ( $\mathrm{CV}=1.638)$, and HIV/AIDS ( $\mathrm{CV}=1.784)$, with the African countries (Nigeria and Sierra Leone) having higher mortality rates than Europe and East Asia. According to the WHO report for 2019, Japan has a negligible mortality rate for HIV/AIDS compared to 32.4 deaths per age-standardized 100,000 people in Sierra Leone. Stroke and ischemic heart disease cause the highest deaths in all the nine populations, with the United Kingdom and Spain having the lowest mortality rates 
among the nine countries. Mortality rates from self-harm have the lowest variation among the nine countries studied here.

\section{Differences in Predicted Polygenic Disease Risk}

Genetic prediction of disease risk varies across the nine populations (Fig. 1) for all 11 diseases. The predicted polygenic disease risk distributions are standardized, with a global mean $(z$-score $=0)$. Here, positive z-scores indicate predicted polygenic disease risks higher than the mean global predicted risk, and negative z-scores indicate risks lower than the mean (Table S1 lists the mean z-score of risk of each of the nine populations for the 11 diseases). Predicted polygenic disease risks are similar for populations within the same continent but differ among continental groups. For example, predicted polygenic risks for chronic kidney diseases vary by continent: African, East Asian, and American populations have higher predicted risks than South Asians and Europeans. Polygenic disease risk for lung cancer shows a wide distribution in European populations, with quite a few individuals with very high predicted risk scores, along with a high mean predicted risk for GBR and IBS populations. Europeans exhibit a higher predicted polygenic disease risk for lung cancer on a continental scale than non-Europeans ( $\mathrm{p}$-value $=3.43 \times 10^{-14}$, Mann-Whitney U Test). Similarly, ischemic heart disease, colorectal cancer, and Alzheimer's disease also show higher predicted polygenic disease risks in Europeans than non-Europeans ( $p$-values for the MannWhitney $U$ Test of each disease are available in Table S2). Chronic obstructive pulmonary disease narrowly passes the significance threshold to show higher risks in Europe with a p-value of 0.048 (Mann-Whitney U Test). Breast cancer, stroke, and chronic kidney disease have similar predicted polygenic risk score distributions in European, South Asian, and East Asian populations (Table S1). Europeans have lower predicted polygenic risks for type 1 diabetes $\left(p\right.$-value $=5.3 \times 10^{-3}$, Mann-Whitney $U$ Test) and type 2 diabetes ( $\mathrm{p}$-value $=2.74 \times 10^{-9}$, Mann-Whitney $U$ Test) than all nonEuropeans, combined. Of the diseases studied here, only hypertensive heart disease does not show significant differences in predicted polygenic disease risks between Europeans and non-Europeans ( $p$-value $=0.556$, Mann-Whitney $U$ Test). Overall, we 
see considerable variation in genetic predictions of disease risks within individual populations and among different continental groups.

\section{Evidence for Polygenic Adaptation}

MixMapper was used to generate the admixture graph for the nine populations (Fig. 2). The graph indicated that the 1KGP population from Peru (PEL) is admixed. The graph topology showed an early split of African and non-African populations, with the nonAfricans further branching into European and Asian groups. According to the admixture graph produced by MixMapper, the Asian branch further divides into East and South Asian sub-branches.

The strength of selection in each branch of the admixture graph was obtained from PolyGraph for all 11 disease traits (Fig. 2). PolyGraph detects adaptation of polygenic traits due to shifts in allele frequency of multiple loci using an admixture graph framework that considers historical divergence of populations. Although PolyGraph identifies weak signals of polygenic adaptation in all 11 traits, the FDR adjusted qvalues do not pass the threshold of significance (q-value < 0.05) for any of the diseases studied here. We note that the raw p-value for ischemic heart disease is 0.01 over the entire admixture graph, but that it does not reach statistical significance once we correct for multiple testing (FDR-adjusted $q$-value $=0.11$ ). Polygraph's overall $p$-values and the FDR adjusted q-values for each disease are listed in Table 2.

While overall signals of polygenic adaptation are weak, certain branches of the admixture graph show detectable signals of adaptation for some diseases (branchspecific statistics from PolyGraph for each disease are listed in Table S3). Of the two major heart diseases we analyzed, both ischemic heart disease and hypertensive heart disease show a negative signal of adaptation for branches that ultimately lead to PEL. The branches leading to GBR and IBS for lung cancer show positive selection signals, consistent with the increased predicted polygenic risk for lung cancer in Europeans. Adaptation signals for breast cancer are negligible in all the branches of the admixture graph. Similarly, type 1 diabetes is also found to have evolved neutrally, although 
predictive risks show Europeans are at a slightly higher risk of getting the disease. Thus, although PolyGraph reports weak branch-specific selection signals for individual diseases, the overall pattern is that polygenic adaptation is not a driver of disease disparities among populations.

\section{Drivers of Disparity in Mortality Rates}

Disparities in disease mortality rates arise from multiple socioeconomic and genetic factors. To test how socioeconomic status influences mortality rates, correlations of HDI to mortality rates were calculated. The mortality rates of the top 20 causes of death in the nine representative populations can mostly be explained by the countries' HDI (Fig. 3A). Mortality rates of colorectal cancer have the highest positive correlation to HDI ( $r=$ 0.74), while mortality rates of road injuries have the highest negative correlation to HDI $(r=-0.957)$. The negative correlation of road injury with HDI should be interpreted with caution, keeping in mind that mortality rates do not reflect incidence rates. Underdeveloped countries can have higher mortality rates from road injuries due to the lack of emergency medical treatment in general, despite having a lower incidence of road injuries than developed countries. Alzheimer's disease, lung cancer, and stomach cancer show a positive correlation with HDI, where highly developed countries have higher mortality rates from these diseases (Table S4). Apart from these four, all other causes of death show a negative correlation with HDI, indicating countries with lower development index have higher mortality rates. An interesting observation is that mortality rates of self-harm are largely independent of HDI. Highly negative correlations of mortality and HDI for diseases like tuberculosis $(r=-0.781)$ and HIV $(r=-0.842)$ are consistent with the knowledge that under-developed and developing countries bear a higher burden of mortality from infectious diseases. Similarly, neonatal diseases $(r=-$ 0.935) and diarrhea $(r=-0.914)$ are major causes of infant death in under-developed countries and are consistent with correlations with HDI. Thus, socioeconomic factors alone play a major role in determining mortality disparities among populations.

We also examine the correlations of predicted polygenic disease risks and mortality rates (Fig. 3B). Overall, the magnitudes of these correlations are lower than that of HDI 
and mortality rates. Eight out of the ten diseases, including COPD, breast cancer, diabetes, chronic kidney disease, and hypertensive heart disease, show positive correlations between predicted polygenic disease risks and mortality rates, although they are not statistically significant. Stroke and ischemic heart disease are interesting cases with negative correlations of predicted polygenic disease risk and mortality rates. Thus, although eight diseases show a weak genetic contribution to disparities in mortality, genetic predictions are inconsistent with epidemiological trends when it comes to stroke and ischemic heart disease. Overall, our results indicate that both socioeconomic and genetic factors play a role in determining country-level mortality rates.

\section{Discussion}

Drivers of disparities in disease incidence and mortality rates worldwide are multifactorial with socioeconomic, demographic, environmental, and genetic aspects (37). Contributions of genetics to disease disparities are driven by a complex combination of natural selection, genetic drift, founder effect, and more (효). Here, we demonstrate the role of polygenic adaptation in shaping disparities in disease mortality worldwide, and the study has provided four key results. First, in analyzing the top 20 causes of death, mortality rates present considerable differences among countries. Mortalities from infectious diseases like diarrhea and tuberculosis vary greatly between continents. On the other hand, self-harm exhibited the lowest variation in mortality rates worldwide. Second, predicted polygenic risk scores for the 11 common diseases depict significant differences between European and non-European populations. The distributions of predicted polygenic risks are consistent within continents but differ among continental populations. Third, although there exist weak branch-specific signatures of selection for some diseases, the overall pattern is that polygenic adaptation is not a major driver of differences in disease risk across populations. And finally, we show that disparities in mortality rates are highly correlated with a country's $\mathrm{HDI}$, indicating socioeconomic and environmental factors are strong drivers of disparities. 
Predicted polygenic disease risks of complex diseases like diabetes and lung cancer often vary among populations (Fig. 1) (39). This arises from differences in allele frequencies of disease-associated loci in different populations. For example, the $\mathrm{C}$ allele (rs7901695) at the TCF7L2 locus for type 2 diabetes has an almost 40-fold increase in its allele frequency from 0.013 in the Chinese populations (CHB) to 0.488 in the African population (13), which contributes to the general pattern of higher predicted risks of type 2 diabetes in African than in East Asian populations (Fig. 1). Although we focus on differences between populations, considerable variation in predicted polygenic disease risk exists within each population, most notable in the wide distribution of predicted risks for lung cancer in Europeans (GBR and IBS) (Fig. 1). Consequently, while polygenic risk prediction has been shown to identify individuals at high risk of a disease (40), caution should be taken when trying to extend these results to broader populations (this is known as the "Ecological Fallacy" of inferring individual data from an aggregate (41))). Nevertheless, polygenic predictions of disease risks tend to be positively correlated with mortality rates (Fig. 3B).

Differences in polygenic disease risk can be due to multiple evolutionary forces, polygenic adaptation being one of them. While our results suggest weak selection for certain diseases in specific evolutionary branches, the overall lack of statistical significance leads us to rule out polygenic adaptation as a significant evolutionary cause of disease disparities. Selection of polygenic traits is distributed across multiple loci. While some loci have a greater influence on the trait with strong selection acting on them, the total selection of a polygenic trait is often mitigated by the alleles with weaker selection, making it difficult to identify overall signals of selection. This contrasts with some well-known Mendelian diseases like sickle cell anemia, where strong selection on a single locus has increased its prevalence in the African populations due to natural selection on genetic resistance to malaria (42).

Although we obtain compelling results on the drivers of disease disparity, we are aware of certain caveats in our methods. First, we study differences in mortality rates in 
populations instead of disparities in incidence rates. The reader should be mindful that while countries have disparities in mortality rates from diseases, there might not be equivalent disparities in incidence rates. Second, for all the common disease studies, well-powered GWASs across multiple populations were not available, and thus we focused on GWASs performed in European populations. Finally, the choice of our nine representative populations is highly dependent on the availability of genetic data from these populations. As more GWAS are performed in varied populations worldwide, future studies will be able to take a more detailed look at polygenic adaptation patterns and genetic influences of disease disparities.

\section{Conclusion and Implications:}

Disparities in disease mortality rates worldwide arise from multiple factors, and here we show that natural selection and polygenic adaptation are not primary contributors to such disparities. We expect to form a more refined idea of how genetics and polygenic adaptation influence disease disparities as newer data sets become available in the future. But until then, socioeconomic and developmental factors should be thoroughly studied to understand the roots of such disparities. To conclude, even though populations have experienced unique evolutionary histories and many common causes of diseases are heritable, our results indicate that most health disparities are driven by factors other than polygenic adaptation.

\section{Funding and Conflict of Interest:}

This work was supported by an NIH MIRA grant to Joseph Lachance (R35GM133727). The funders did not have any role in the design, analysis or writing of this article. We declare no conflict of interests for both the authors.

\section{Acknowledgments}

We thank Aaron Pfennig, Mimi Brown, and Shashwat Nagar for their helpful comments and suggestions during the writing of this manuscript. 


\section{References}

1. Crimmins E, Kim JK, Vasunilashorn S; Biodemography: new approaches to understanding trends and differences in population health and mortality. Demography 2010;47 Suppl:S41-64. doi: 10.1353/dem.2010.0005.

2. Mullins CD, Blatt L, Gbarayor CM, et al.; Health disparities: a barrier to high-quality care. Am J Health Syst Pharm 2005;62(18):1873-82. doi: 10.2146/ajhp050064.

3. Phelan JC, Link BG; Controlling disease and creating disparities: a fundamental cause perspective. J Gerontol B Psychol Sci Soc Sci 2005;60 Spec No 2:27-33. doi: 10.1093/geronb/60.special_issue_2.s27.

4. Mummert A, Esche E, Robinson J, et al.; Stature and robusticity during the agricultural transition: evidence from the bioarchaeological record. Econ Hum Biol 2011;9(3):284-301. doi: 10.1016/j.ehb.2011.03.004.

5. Armstrong GL, Conn LA, Pinner RW; Trends in infectious disease mortality in the United States during the 20th century. JAMA 1999;281(1):61-6. doi: 10.1001/jama.281.1.61.

6. Corbett S, Courtiol A, Lummaa V, et al.; The transition to modernity and chronic disease: mismatch and natural selection. Nat Rev Genet 2018;19(7):419-430. doi: 10.1038/s41576-018-0012-3.

7. Bigna JJ, Noubiap JJ; The rising burden of non-communicable diseases in subSaharan Africa. Lancet Glob Health 2019;7(10):e1295-e1296. doi: 10.1016/S2214$109 \times(19) 30370-5$.

8. Kim AS, Johnston SC; Global variation in the relative burden of stroke and ischemic heart disease. Circulation 2011;124(3):314-23. doi:

10.1161/CIRCULATIONAHA.111.018820.

9. Rebbeck TR; Prostate Cancer Genetics: Variation by Race, Ethnicity, and Geography. Semin Radiat Oncol 2017;27(1):3-10. doi:

10.1016/j.semradonc.2016.08.002.

10. Nicholas SB, Kalantar-Zadeh K, Norris KC; Socioeconomic disparities in chronic kidney disease. Adv Chronic Kidney Dis 2015;22(1):6-15. doi:

10.1053/j.ackd.2014.07.002. 
11. Lewis J, Hoover J, MacKenzie D; Mining and Environmental Health Disparities in Native American Communities. Curr Environ Health Rep 2017;4(2):130-141. doi: 10.1007/s40572-017-0140-5.

12. Struewing JP, Hartge P, Wacholder S, et al.; The risk of cancer associated with specific mutations of BRCA1 and BRCA2 among Ashkenazi Jews. N Engl J Med 1997;336(20):1401-8. doi: 10.1056/NEJM199705153362001.

13. Adeyemo A, Rotimi C; Genetic variants associated with complex human diseases show wide variation across multiple populations. Public Health Genomics 2010;13(2):72-9. doi: 10.1159/000218711.

14. Gibson G; Hints of hidden heritability in GWAS. Nat Genet 2010;42(7):558-60. doi: 10.1038/ng0710-558.

15. Shifman S, Kuypers J, Kokoris M, et al.; Linkage disequilibrium patterns of the human genome across populations. Hum Mol Genet 2003;12(7):771-6. doi: $10.1093 / \mathrm{hmg} / \mathrm{ddg} 088$.

16. McCarthy MI, Abecasis GR, Cardon LR, et al.; Genome-wide association studies for complex traits: consensus, uncertainty and challenges. Nat Rev Genet 2008;9(5):356-69. doi: 10.1038/nrg2344.

17. Chande AT, Wang L, Rishishwar L, et al.; GlobAl Distribution of GEnetic Traits (GADGET) web server: polygenic trait scores worldwide. Nucleic Acids Res 2018;46(W1):W121-W126. doi: 10.1093/nar/gky415.

18. Lewis CM, Vassos E; Polygenic risk scores: from research tools to clinical instruments. Genome Med 2020;12(1):44. doi: 10.1186/s13073-020-00742-5.

19. Berg JJ, Coop G; A population genetic signal of polygenic adaptation. PLoS Genet 2014;10(8):e1004412. doi: 10.1371/journal.pgen.1004412.

20. World Health Organisation. Global Health Estimates 2020: Deaths by Cause, Age, Sex, by Country and by Region, 2000-2019.

https:/www.who.int/data/gho/data/themes/mortality-and-global-healthestimates/ghe-leading-causes-of-death (Date Accessed 2020 Accessed, date last accessed)

21. United Nations Development Programme. Human Development Report 2020. The Next Frontier: Human Development and the Anthropocene. 


\section{http://hdr.undp.org/en/content/human-development-report-2020 (Date Accessed} 2020 Accessed, date last accessed)

22. Lambert JC, Ibrahim-Verbaas CA, Harold D, et al.; Meta-analysis of 74,046 individuals identifies 11 new susceptibility loci for Alzheimer's disease. Nat Genet 2013;45(12):1452-8. doi: 10.1038/ng.2802.

23. McKay JD, Hung RJ, Han Y, et al.; Large-scale association analysis identifies new lung cancer susceptibility loci and heterogeneity in genetic susceptibility across histological subtypes. Nat Genet 2017;49(7):1126-1132. doi: 10.1038/ng.3892.

24. Malik R, Chauhan G, Traylor M, et al.; Multiancestry genome-wide association study of 520,000 subjects identifies 32 loci associated with stroke and stroke subtypes. Nat Genet 2018;50(4):524-537. doi: 10.1038/s41588-018-0058-3.

25. van der Harst P, Verweij N; Identification of 64 Novel Genetic Loci Provides an Expanded View on the Genetic Architecture of Coronary Artery Disease. Circ Res 2018;122(3):433-443. doi: 10.1161/CIRCRESAHA.117.312086.

26. Xue A, Wu Y, Zhu Z, et al.; Genome-wide association analyses identify 143 risk variants and putative regulatory mechanisms for type 2 diabetes. Nat Commun 2018;9(1):2941. doi: 10.1038/s41467-018-04951-w.

27. Giri A, Hellwege JN, Keaton JM, et al.; Trans-ethnic association study of blood pressure determinants in over 750,000 individuals. Nat Genet 2019;51(1):51-62. doi: 10.1038/s41588-018-0303-9.

28. Law PJ, Timofeeva M, Fernandez-Rozadilla C, et al.; Association analyses identify 31 new risk loci for colorectal cancer susceptibility. Nat Commun 2019;10(1):2154. doi: 10.1038/s41467-019-09775-w.

29. Mavaddat N, Michailidou K, Dennis J, et al.; Polygenic Risk Scores for Prediction of Breast Cancer and Breast Cancer Subtypes. Am J Hum Genet 2019;104(1):21-34. doi: 10.1016/j.ajhg.2018.11.002.

30. Sakornsakolpat P, Prokopenko D, Lamontagne M, et al.; Genetic landscape of chronic obstructive pulmonary disease identifies heterogeneous cell-type and phenotype associations. Nat Genet 2019;51(3):494-505. doi: 10.1038/s41588-0180342-2. 
31. Wuttke M, Li Y, Li M, et al.; A catalog of genetic loci associated with kidney function from analyses of a million individuals. Nat Genet 2019;51(6):957-972. doi: 10.1038/s41588-019-0407-x.

32. Chiou J, Geusz RJ, Okino ML, et al.; Interpreting type 1 diabetes risk with genetics and single-cell epigenomics. Nature 2021;594(7863):398-402. doi: 10.1038/s41586021-03552-w.

33. Hinrichs AS, Karolchik D, Baertsch R, et al.; The UCSC Genome Browser Database: update 2006. Nucleic Acids Res 2006;34(Database issue):D590-8. doi: 10.1093/nar/gkj144.

34. Racimo F, Berg JJ, Pickrell JK; Detecting Polygenic Adaptation in Admixture Graphs. Genetics 2018;208(4):1565-1584. doi: 10.1534/genetics.117.300489.

35. Pers TH, Timshel P, Hirschhorn JN; SNPsnap: a Web-based tool for identification and annotation of matched SNPs. Bioinformatics 2015;31(3):418-20. doi: 10.1093/bioinformatics/btu655.

36. Lipson M, Loh PR, Levin A, et al.; Efficient moment-based inference of admixture parameters and sources of gene flow. Mol Biol Evol 2013;30(8):1788-802. doi: 10.1093/molbev/mst099.

37. Adler NE, Rehkopf DH; U.S. disparities in health: descriptions, causes, and mechanisms. Annu Rev Public Health 2008;29:235-52. doi:

10.1146/annurev.publhealth.29.020907.090852.

38. Benton ML, Abraham A, LaBella AL, et al.; The influence of evolutionary history on human health and disease. Nat Rev Genet 2021;22(5):269-283. doi: 10.1038/s41576-020-00305-9.

39. Martin AR, Gignoux CR, Walters RK, et al.; Human Demographic History Impacts Genetic Risk Prediction across Diverse Populations. Am J Hum Genet 2020;107(4):788-789. doi: 10.1016/j.ajhg.2020.08.020.

40. Khera AV, Chaffin M, Aragam KG, et al.; Genome-wide polygenic scores for common diseases identify individuals with risk equivalent to monogenic mutations. Nat Genet 2018;50(9):1219-1224. doi: 10.1038/s41588-018-0183-z.

41. Piantadosi S, Byar DP, Green SB; The ecological fallacy. Am J Epidemiol 1988;127(5):893-904. doi: 10.1093/oxfordjournals.aje.a114892. 
medRxiv preprint doi: https://doi.org/10.1101/2021.12.10.21267630; this version posted December 14, 2021. The copyright holder for this preprint (which was not certified by peer review) is the author/funder, who has granted medRxiv a license to display the preprint in perpetuity. It is made available under a CC-BY-NC-ND 4.0 International license .

\section{Allison AC; Protection afforded by sickle-cell trait against subtertian malareal} infection. Br Med J 1954;1(4857):290-4. doi: 10.1136/bmj.1.4857.290. 
medRxiv preprint doi: https://doi.org/10.1101/2021.12.10.21267630; this version posted December 14, 2021. The copyright holder for this preprint (which was not certified by peer review) is the author/funder, who has granted medRxiv a license to display the preprint in perpetuity.

It is made available under a CC-BY-NC-ND 4.0 International license .

Tables

Table 1

\begin{tabular}{|c|c|c|c|c|c|c|c|c|c|c|}
\hline Causes of death & $\begin{array}{l}\text { United } \\
\text { Kingdom }\end{array}$ & Spain & Nigeria & $\begin{array}{l}\text { Sierra } \\
\text { Leone }\end{array}$ & Bangladesh & $\begin{array}{c}\text { Sri } \\
\text { Lanka }\end{array}$ & China & Japan & Peru & CV \\
\hline HIV/AIDS & 0.2 & 0.8 & 26.8 & 34.2 & 0.4 & 0.2 & 1.6 & 0 & 2.6 & 1.784 \\
\hline Tuberculosis & 0.2 & 0.2 & 99.1 & 43.6 & 25.9 & 3.5 & 1.9 & 0.5 & 7.1 & 1.638 \\
\hline Diarrheal diseases & 0.9 & 0.6 & 79 & 91.1 & 29.6 & 2.5 & 0.7 & 0.5 & 3.3 & 1.575 \\
\hline Neonatal conditions & 3 & 2.2 & 36 & 34.2 & 19 & 4 & 3.8 & 0.7 & 5.2 & 1.177 \\
\hline $\begin{array}{l}\text { Lower respiratory } \\
\text { infections }\end{array}$ & 20.4 & 8 & 98.1 & 131.4 & 23 & 20.4 & 11.3 & 16.6 & 44.2 & 1.05 \\
\hline Cirrhosis of the liver & 7.9 & 4.8 & 42 & 33.3 & 16.6 & 5 & 7.6 & 4.8 & 19.3 & 0.87 \\
\hline Diabetes mellitus & 3.6 & 5 & 33.5 & 38 & 25.5 & 47.3 & 8.6 & 1.4 & 13.3 & 0.865 \\
\hline Road injury & 2.8 & 3.1 & 27.3 & 41.6 & 16.7 & 18.1 & 15.1 & 2.2 & 13.4 & 0.826 \\
\hline $\begin{array}{l}\text { Hypertensive heart } \\
\text { disease }\end{array}$ & 3 & 4.7 & 16.1 & 20.3 & 13.3 & 4.1 & 16.8 & 1.1 & 3.1 & 0.802 \\
\hline $\begin{array}{l}\text { Trachea, bronchus, } \\
\text { lung cancers }\end{array}$ & 24.7 & 22.8 & 1.4 & 2.4 & 10.2 & 6.6 & 36.6 & 18.1 & 9.5 & 0.796 \\
\hline Stroke & 20.2 & 18.4 & 88.7 & 120.1 & 119.2 & 26.6 & 110.8 & 23.2 & 22.6 & 0.77 \\
\hline Stomach cancer & 3.3 & 5.2 & 2.5 & 7 & 5.5 & 4.9 & 20.5 & 11.5 & 15.1 & 0.723 \\
\hline Kidney diseases & 2.9 & 5.5 & 23.9 & 30.2 & 9.1 & 26.2 & 10.4 & 7.6 & 21.3 & 0.666 \\
\hline $\begin{array}{l}\text { Chronic obstructive } \\
\text { pulmonary disease }\end{array}$ & 19.8 & 12.3 & 20.8 & 27.4 & 41.7 & 37 & 54.2 & 12.7 & 7.2 & 0.603 \\
\hline Falls & 4.3 & 2.5 & 8.5 & 9 & 2.6 & 3.9 & 8 & 2 & 3.8 & 0.559 \\
\hline $\begin{array}{l}\text { Colon and rectum } \\
\text { cancers }\end{array}$ & 12.1 & 14.3 & 4.3 & 5.4 & 3.6 & 3.4 & 13 & 13.6 & 7.9 & 0.535 \\
\hline $\begin{array}{l}\text { Ischemic heart } \\
\text { disease }\end{array}$ & 43.1 & 34.9 & 100.9 & 139.4 & 94.3 & 101.3 & 97.6 & 30.6 & 40 & 0.515 \\
\hline Self-harm & 6.9 & 5.3 & 6.9 & 11.3 & 3.9 & 12.9 & 6.7 & 12.2 & 2.7 & 0.48 \\
\hline $\begin{array}{l}\text { Alzheimer disease } \\
\text { and other dementias }\end{array}$ & 42.7 & 21.5 & 19.4 & 19.3 & 13.9 & 27.6 & 17.4 & 7.9 & 16.2 & 0.477 \\
\hline Breast cancer & 9.4 & 6.9 & 10.4 & 14.9 & 5.3 & 5.3 & 4.7 & 5.4 & 6 & 0.445 \\
\hline
\end{tabular}


medRxiv preprint doi: https://doi.org/10.1101/2021.12.10.21267630; this version posted December 14, 2021. The copyright holder for this preprint (which was not certified by peer review) is the author/funder, who has granted medRxiv a license to display the preprint in perpetuity.

It is made available under a CC-BY-NC-ND 4.0 International license .

508

509

510

511

512

513

514

515

Table 1. Disparities in mortality rates for the top 20 worldwide causes of death. The top 20 causes of death from the World Health Organization Report of 2019 are reported here. Population-specific mortality rates for each disease are age-standardized per 100,000 individuals. The 1000 Genomes Project population codes for each country are United Kingdom (GBR), Spain (IBS), Nigeria (YRI), Sierra Leone (MSL), Bangladesh (BEB), Sri Lanka (STU), China (CHB), Japan (JPT) and Peru (PEL). CV stands for the coefficient of variation of mortality rates. Note that mortality for type 1 diabetes and type 2 diabetes are reported jointly as diabetes mellitus. 
medRxiv preprint doi: https://doi.org/10.1101/2021.12.10.21267630; this version posted December 14, 2021. The copyright holder for this preprint (which was not certified by peer review) is the author/funder, who has granted medRxiv a license to display the preprint in perpetuity.

It is made available under a CC-BY-NC-ND 4.0 International license .

\section{Table 2}

\begin{tabular}{|c|c|c|c|c|}
\hline Disease & GWAS source & \# of SNPs & $\begin{array}{l}\text { Overall } \\
\text { p-value }\end{array}$ & $\begin{array}{l}\text { FDR adjusted } \\
\text { q-value }\end{array}$ \\
\hline Ischemic heart disease & 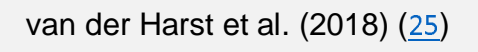 & 148 & 0.01 & 0.11 \\
\hline Stroke & Malik et al. (2018) (24) & 26 & 0.176 & 0.323 \\
\hline $\begin{array}{l}\text { Chronic obstructive } \\
\text { pulmonary disease }\end{array}$ & Sakornsakolpat et al. (2019) (프) & 82 & 0.829 & 0.829 \\
\hline $\begin{array}{l}\text { Trachea, bronchus, lung } \\
\text { cancers }\end{array}$ & McKay et al. (2017) (23) & 115 & 0.065 & 0.297 \\
\hline $\begin{array}{l}\text { Alzheimer disease and } \\
\text { other dementias }\end{array}$ & Lambert et al. (2013) (22) & 19 & 0.64 & 0.782 \\
\hline Type 1 Diabetes mellitus & Chiou et al. (2021) (르) & 33 & 0.741 & 0.815 \\
\hline Type 2 Diabetes mellitus & Xue et al. (2018) (26) & 139 & 0.331 & 0.52 \\
\hline Kidney diseases & Wuttke et al. (2019) (31) & 308 & 0.152 & 0.323 \\
\hline $\begin{array}{l}\text { Hypertensive heart } \\
\text { disease }\end{array}$ & Giri et al. (2019) (27) & 258 & 0.081 & 0.297 \\
\hline $\begin{array}{l}\text { Colon and rectum } \\
\text { cancers }\end{array}$ & Law et al. (2019) (28) & 40 & 0.175 & 0.323 \\
\hline Breast cancer & Mavaddat et al. (2019) (르) & 313 & 0.485 & 0.667 \\
\hline
\end{tabular}

Table 2. Tests of polygenic adaptation for 11 common diseases. The number of disease-associated loci reported and the reference GWAS are listed for each disease. Polygraph reports the overall $p$-value as a measure of the significance of polygenic adaptation in the entire admixture graph. FDR adjusted q-values correct for multiple testing. 
medRxiv preprint doi: https://doi.org/10.1101/2021.12.10.21267630; this version posted December 14, 2021. The copyright holder for this preprint (which was not certified by peer review) is the author/funder, who has granted medRxiv a license to display the preprint in perpetuity.

It is made available under a CC-BY-NC-ND 4.0 International license .

\section{Figures}

Figure 1
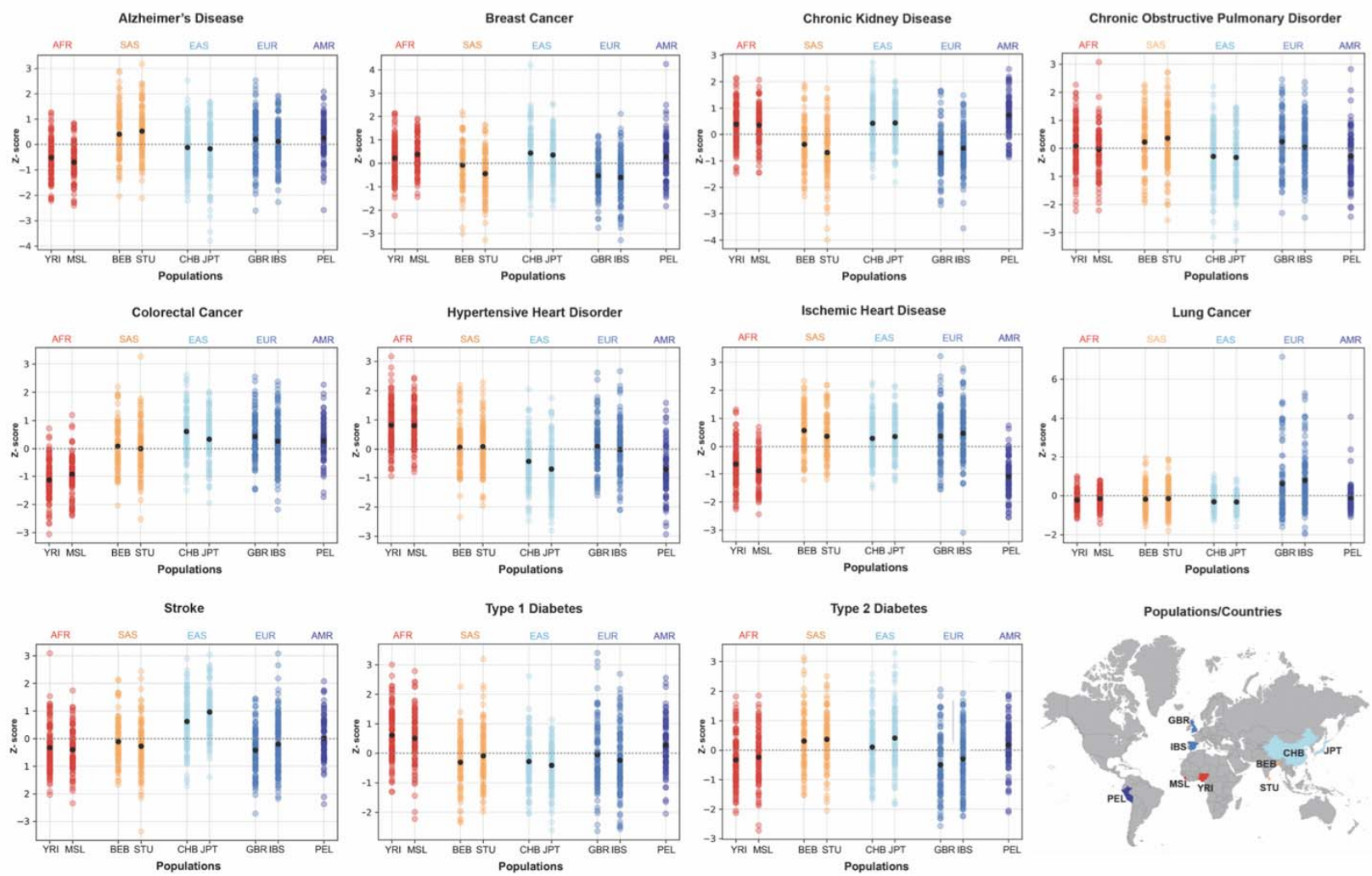

Figure 1. Predicted polygenic risks for 11 common diseases over the nine representative populations. Z-score distributions of predicted polygenic disease risks are shown here. Each dot in the distribution represents an individual. Distributions above the global mean $(z$-score $=0)$ indicate higher risks, whereas those below zero indicate lower disease risks. Different colors indicate continental superpopulations. 


\section{Figure 2}
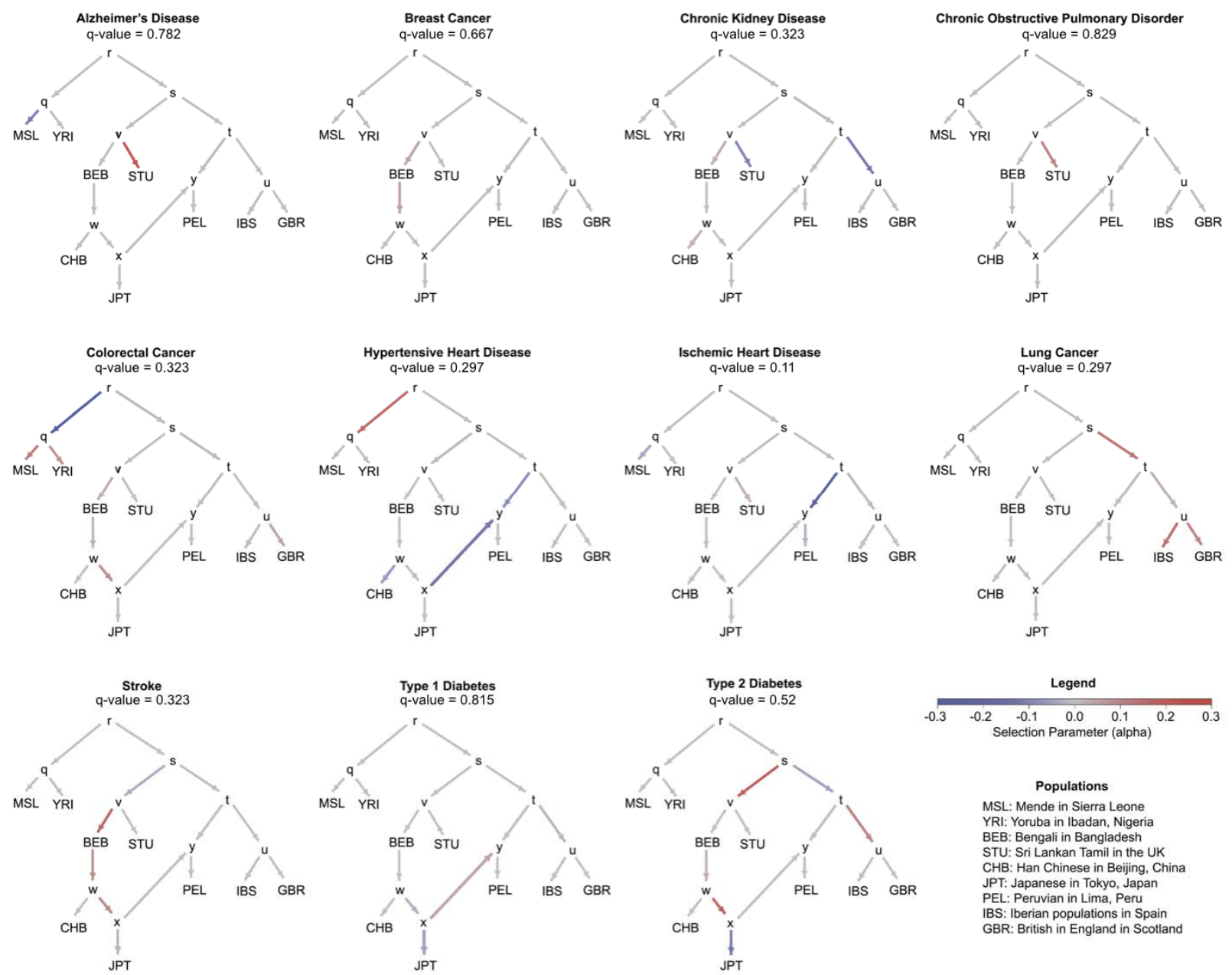

Figure 2. Minimal evidence of natural selection acting on common polygenic diseases. MixMapper was used to generate the admixture graph and PolyGraph was used to test for polygenic signatures of adaptation. FDR adjusted q-values are above 0.05 for all nine diseases. The selection parameter alpha reports a product of the selection coefficient for the advantageous allele and the duration of the selective process. Positive values of alpha indicate positive selection in the branch while negative values are indicative of negative selection acting on a trait. 
A

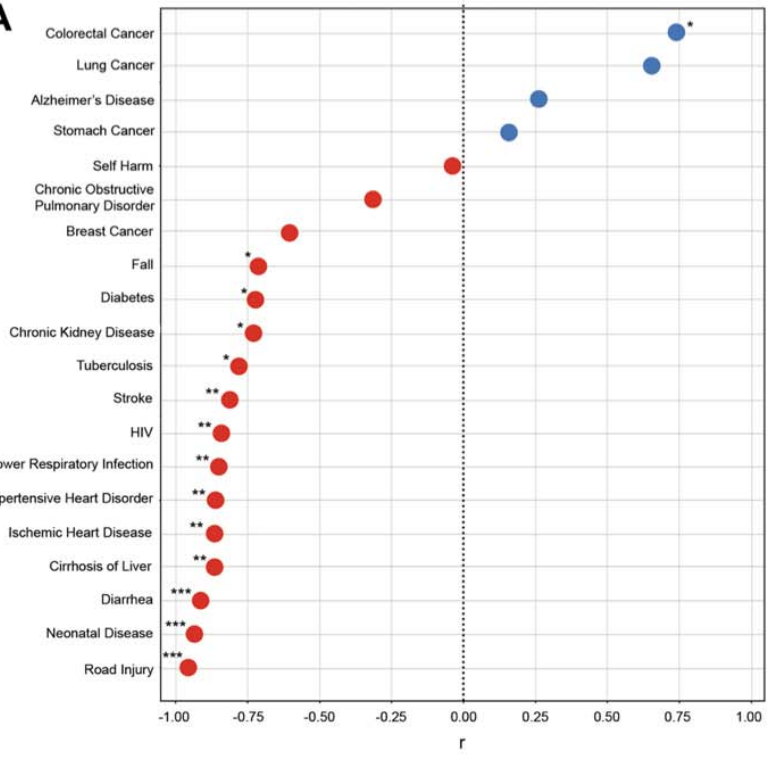

B

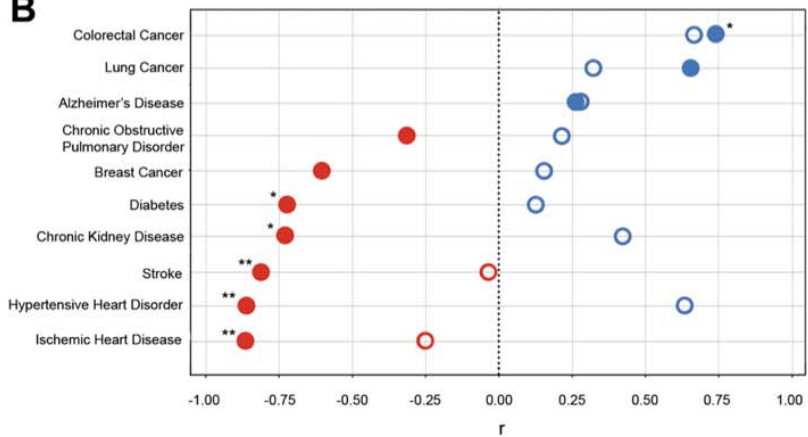

Correlation between
HDI and mortality rate
PRS and mortality rate

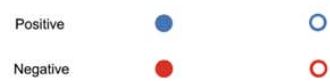

Figure 3. Correlations of mortality rates with Human Development Index (HDI) statistics and predicted genetic disease risks. (A) 14 out of the top 20 causes of death from the 2019 World Health Organization report show a statistically significant correlation between country-specific mortality rates and HDI. (B) Correlations of mortality with HDI and polygenic risk scores. Filled circles indicate correlations between mortality rates and $\mathrm{HDI}$, and open circles indicate correlations between mortality rates and PRS (positive correlations in blue, negative correlations in red). ${ }^{*}$ indicates $p$-value $<0.05,{ }^{* *}$ indicates $p$-value $<0.01$ and ${ }^{* * *}$ indicates $p$-value $<0.001$. 